\title{
INTERNAL CONVERSE IN MODERN MEDIA DISCOURSE
}

\author{
Olga A. Prokhvatilova
}

Lomonosov Moscow State University, Moscow, Russia

\begin{abstract}
The article reveals specificity of internal converse practice in the media discourse. The converse is defined as a speech-and-cognitive category that characterizes a constructive principle of the media text manifested in insertion of other person's utterances into the monospeech of a journalist. It is stated that the major means of converse practice is citing direct speech of some other person, which enables precise marking of citation boundaries in media texts. The other person's utterance insertion is marked by the use of reporting verbs that nominate processes of saying or communication in oral or written forms of media discourse, indicating the source of citation with introductory constructions, as well as the names and nicknames of radio listeners who sent their questions. Direct speech may be introduced into the author's text without any special linguistic markers. The sources of quoting relevant for the media text are revealed, including radio listeners, journalists, writers, economists, public and political figures, heroes of modern books and popular movies, mass media. Four functions of the cited utterances are considered relevant for the modern media text: compositional, authoritarian, interpretive and constructive. The types of converse relations that arise between the author's and other person's cited speech are determined.

Key words: media text, converse category, types of converse, authorization, converse representation means, citation sources, internal converse practice.

Citation. Prokhvatilova O.A. Internal Converse in Modern Media Discourse. Vestnik Volgogradskogo gosudarstvennogo universiteta. Seriya 2. Yazykoznanie [Science Journal of Volgograd State University. Linguistics], 2020, vol. 19, no. 2, pp. 150-158. (in Russian). DOI: https://doi.org/10.15688/jvolsu2.2020.2.13

УДК 811.161.1’27

Дата поступления статьи: 01.12.2019

ББК 81.411 .2

Дата принятия статьи: 28.02.2020
\end{abstract}

\section{ВНУТРЕННЯЯ ДИАЛОГИЧНОСТЬ СОВРЕМЕННОЙ МЕДИАРЕЧИ}

\section{Ольга Александровна Прохватилова}

Московский государственный университет им. М.В. Ломоносова, г. Москва, Россия

\begin{abstract}
Аннотация. В статье раскрывается специфика внутренней диалогичности медиатекста. Диалогичность понимается как речемыслительная функционально-семантическая категория, в которой проявляются те или иные признаки диалога, и рассматривается как конструктивный принцип медиатекста. Показано, что средством создания внутренней диалогичности медиатекста выступает введенная в монолог журналиста чужая речь. Установлено, что приоритетной формой передачи чужого слова в медиатексте является прямая речь, которая позволяет четко обозначить границы цитирования. Выявлено, что в качестве сигналов ввода чужого слова в авторский контекст выступают глаголы письма и речи, вводные конструкции с указанием на источник цитирования, а также имена и ники приславших свои вопросы радиослушателей. Описаны случаи, когда чужая речь включается в авторский контекст без каких-либо специальных средств. Раскрыты актуальные для медиатекста источники цитирования: высказывания радиослушателей, журналистов, писателей, экономистов, общественных и политических деятелей, героев современных книг и популярных кинофильмов, тексты СМИ. Продемонстрировано, что для современного медиатекста релевантны четыре функции чужого слова: композиционная, авторитарная, интерпретирующая и конструктивная. Определены типы диалогических отношений, которые возникают между словом автора и чужой речью.

Ключевые слова: медиатекст, диалогичность, типы диалогичности, авторизация, средства внутренней диалогичности, источники цитирования, функции внутренней диалогичности.
\end{abstract}


Цитирование. Прохватилова О. А. Внутренняя диалогичность современной медиаречи // Вестник Волгоградского государственного университета. Серия 2, Языкознание. - 2020. - Т. 19, № 2. - С. 150-158. - DOI: https://doi.org/10.15688/jvolsu2.2020.2.13

\section{Введение}

Современные исследователи медиатекста относят диалогичность к числу его конструктивных принципов [Дускаева 2012; Коньков 2016; и др.]. Между тем в настоящий момент в описании специфики этого феномена многие вопросы остаются открытыми. Прежде всего, это касается определения самого понятия «диалогичность».

В специальной литературе существуют различные трактовки сущности диалогичности. Так, в некоторых работах по стилистике диалогичность монологического контекста признается стилистическим приемом и ассоциируется с использованием средств активизации внимания [Славгородская, 1978; Винокур, 1990; и др.]. Диалогичность рассматривается и как выражение в речи многоголосия общения с целью достижения эффективности коммуникации в той или иной сфере общения [Дускаева, 2012]. Однако в большинстве современных лингвистических исследований диалогичность понимается как важнейшая текстовая категория и рассматривается применительно к монологическим структурам текста, в рамках которых актуальны диалогические отношения [Кожина, 1986; Болотнова, 2009; Котюрова, 2010; и др.].

Вместе с тем вопрос о категориальном статусе диалогичности текста не нашел однозначного решения в специальной литературе. Так, диалогичность рассматривается как семантико-стилистическая категория. Основы такого подхода были заложены в работах М.Н. Кожиной (см., например: [Кожина, 1986]), где на материале научных текстов представлено описание языковых средств выражения данной категории, определена ее специфика в аспекте полевого структурирования.

Мы придерживаемся иной точки зрения на диалогичность и трактуем ее как речемыслительную функционально-семантическую категорию, в которой проявляются те или иные признаки диалога. Наш подход основывается на признании существования в высказывании двух симметричных модусных сфер - сферы субъекта речи («я»-сфера) и сферы адресата речи («ты»-сфера), актуализация которых обеспечивает его авторизацию (то есть речевую позицию субъекта речи) или адресацию (то есть направленность речи на адресата).

Опираясь на понятия авторизации и адресации, мы различаем три типа диалогичности - внешнюю, внутреннюю и глубинную, каждая из которых характеризуется набором признаков в плане содержания и комплексом моделей в плане выражения [Прохватилова, 1999]. Если внешняя и внутренняя диалогичность находит воплощение в текстах любой стилистической принадлежности, то глубинная диалогичность присуща в основном религиозным текстам (прежде всего молитве и проповеди) и отражает их специфику. Предлагаемая нами концепция дает системное представление о диалогичности и может быть применена к любому стилистическому материалу.

По нашим наблюдениям, в современном медиатексте диалогичность представлена двумя видами - внешней и внутренней. Статья посвящена рассмотрению внутренней диалогичности.

\section{Материал и методы исследования}

В качестве материала использованы стенограммы прозвучавших на радио «Эхо Москвы» авторских передач «Один» (эфиры от 03.06.2017, ведущий Д. Быков; 25.08.2017, ведущий А. Венедиктов; 25.08.2018, ведущий С. Пархоменко) и «Код доступа» (эфир от 25.08.2018, ведущая Ю. Латынина).

Описание внутренней диалогичности медитекста, которая реализует в монологическом контексте один из основных признаков диалога - реплицирование - и связана с модификациями «я»-сферы высказывания, предполагает анализ введенной в монолог чужой речи как персонифицированного и авторизированного отражения разных смысловых позиций, точек зрения.

Как известно, идея о том, что чужая речь, включенная в авторский монолог, является 


\section{МАТЕРИАЛЫ И СООБЩЕНИЯ}

источником диалогичности текста, принадлежит М.М. Бахтину. Предложенный им подход основывается на понимании чужой речи как высказывания другого субъекта, которое первоначально совершенно самостоятельно и лежит вне данного контекста и которое может восприниматься говорящим как определенная смысловая позиция этого другого субъекта [Бахтин, 1993, с. 125, 140]. При введении чужой речи в монологический контекст происходит «столкновение двух коммуникативных сфер», а именно сфер реальной и воспроизводимой говорящим коммуникаций [Китайгородская, 1993, с. 66]. Вследствие этого в монологе, наряду с авторским планом, появляется план субъекта цитируемого высказывания и создается двуплановость сообщения, разрушающая монологическую монолитность речи и приводящая к возникновению ее диалогичности.

При анализе специфики внутренней диалогичности медиатекста используется методика, разработанная на материале духовной речи [Прохватилова, 1999] и успешно опробированная исследователями диалогичности текстов разной стилистической отнесенности рекламных, научных, художественных (см., например: [Чубай, 2005; Вотрина, 2011; Прохватилова, Фотина, 2016; Фотина, 2016]). В соответствии с этой методикой рассмотрение чужой речи проводится в следующем порядке: 1) раскрываются формы передачи чужого слова; 2) устанавливаются сигналы его ввода в монологический контекст; 3) характеризуются источники цитирования; 4) определяются функции воспроизводимого чужого слова; 5) выявляются типы диалогических отношений, которые возникают при цитировании между авторским и чужим словом.

\section{Результаты и обсуждение}

Проведенный анализ внутренней диалогичности современного медиатекста обнаруживает, что она обусловлена сменой «точек зрения» в монологическом контексте и представляет собой воспроизведение чужой речи. Для введения чужого слова в авторский контекст журналисты используют различные виды прямой и косвенной речи - собственно прямую, полупрямую и собственно косвенную.
Каждый из этих видов, сохраняя автономность авторского и чужого слова и их пространственную обособленность, варьирует модально-синтаксический план воспроизводимого высказывания, его лексические и стилистические особенности.

В нашем материале предпочтение отдается прямой речи, полупрямая и косвенная речь употребляются в единичных случаях. Представляется, что такой выбор обусловлен ситуацией устного общения, в которой прямая речь выступает наиболее надежным средством выделения чужого слова в монологическом контексте, поскольку в ней приводимые автором высказывания других лиц сохраняются полностью, не подвергаясь никакой переработке, например:

(1) Некто Артемий меня спрашивает: «Расскажите про события в Вильнюсе. Неужели посол в Литве настолько большой трус, что не может прийти на увековечение памяти большого государственного деятеля? <...>». Вы знаете, я, если честно, к своему стыду пропустил эту деталь: приходил или не приходил посол России в Литве на открытие этого сквера имени Бориса Немцова в Вильнюсе сегодня... (С. Пархоменко, эфир 25.08.2018).

При этом прямая речь позволяет предельно четко обозначить границы авторского и цитируемого слова, сохраняя модально-синтаксический план первичного высказывания, его лексическое и эмоционально-стилистическое своеобразие. Использование прямой речи свидетельствует о достоверности, полноте, точности передаваемой информации и косвенно выражает уважение к источнику информации.

В полупрямой речи происходит смешение форм прямой и косвенной речи, так как в ней не изменяется лексический состав и грамматический строй чужого слова, но передается оно в виде придаточного предложения, например:

(2) Зато придворный ювелир Карл Фаберже говорил, что «ребята, мне столько заказов на столько бриллиантов и столько драгоценностей, как в первые годы войны, просто нигде и никогда не поступало» (Ю. Латынина, эфир 25.08.2018).

Такая форма ввода чужого слова в монологический контекст характерна для бытового общения и широко используется в художествен- 
ных текстах в речи персонажей. Употребление полупрямой речи при создании внутренней диалогичности в медиатекстах усиливает эффект достоверности цитируемого высказывания, с одной стороны, и создает впечатление непринужденности и непосредственности речи журналиста - с другой.

В собственно косвенной речи чужое слово, сохраняя свою пространственную обособленность в авторском высказывании, локализуется в зависящем от глагола придаточном предложении, например:

(3) Действительно, музыка довольно деревенская. Тут мне кто-то написал, что это вариации на «Кукарачу». Сами вы вариация на «Кукарачу». Это тончайшее мелодическое решение. Это удивительно сложная и изящная аранжировка (С. Пархоменко, эфир 25.08.2018).

Несмотря на то что при употреблении косвенной речи лексические и стилистические особенности высказываний других лиц не сохраняются, первоначальное содержание чужого слова не излагается дословно, подвергаясь либо интерпретации, либо компрессии, границы авторской и цитируемой речи обозначаются четко, поскольку косвенная речь всегда составляет второй компонент синтаксической конструкции и занимает позицию объекта по отношению к авторской вводящей части.

Чужая речь может включаться в авторский контекст различными способами. К ним относятся: нулевой ввод и ввод чужого слова с помощью разноуровневых средств - лексических или синтаксических. Преобладающими метатекстовыми сигналами ввода чужого слова в медиатекстах выступают обычно глаголы письма (nисать, написать), глаголы говорения широкой семантики (говорить, сказать) и глаголы речи, имеющие значение вопроса (спрашивать), например:

(4) Вот Алексей из Москвы пишет: «А можно поинтересоваться, чего это вы все иностранными университетами восхищаетесь? Искренне считаете, что у студентов Казанского, Владимирского, Южно-Уральского, Московского интеллектуальный уровень ниже?» Знаете, Алексей, мой опыт, да и вообще любой опыт любого другого разумного человека, не только мой, показывает, что уровень университета складывается не только из интеллектуаль- ного уровня студентов, но еще и из интеллектуального уровня педагогов, еще из оборудования в этом университете, еще из доступа к информации в этом университете, еще из атмосферы в этом университете, среды в этом университете, порядков в этом университете, традиций в этом университете, много из чего складывается класс университета (С. Пархоменко, эфир 25.08.2018);

(5) Наоборот, когда к нему пришел знакомиться Чуковский - самый знаменитый литературный критик России в это время - и начал ему объяснять, как тот хорошо пишет, Маяковский сказал: «Я все это знаю. Вот тут сидит старичок, он отец девушки, которая мне очень нравится. К нему пойдите и расскажите, какой я хороший. Ему это гораздо важнее» (Д. Быков, эфир 03.06.2017);

(6) Илья спрашивает: «Как, на ваш взгляд, президент Путин относится к Сталину?» Знаете что, я же запросил интервью у Владимира Владимировича для журнала «Дилетант». Исторического. Про его отношение к историческим персонажам (А. Венедиктов, эфир 25.08.2017).

В нашем материале отмечаются единичные случаи использования и других способов ввода чужой речи, например имени или ника приславшего вопрос радиослушателя либо вводной конструкции с указанием на источник цитирования:

(7) Лара 17: «Добрый день, Алексей Алексеевич, как вы относитесь к идее создания на “Эхе” передачи, разоблачающей фейковые новости?» Я не понимаю, что такое отдельная передача, разоблачающая фейковые новости (А. Венедиктов, эфир 25.08.2017);

(8) Я думаю, что Стругацкие поздние, может быть, снисходительнее отнеслись бы к своим героям из «Второго нашествия», потому что, как говорит тот же Виктор Банев, «в истории человечества не так много было периодов, когда люди могли $b b l-$ пивать и закусывать quantum satis» (Д. Быков, эфир 03.06.2017).

Обращает на себя внимание, что примерно четверть от общего объема составляют случаи, когда чужая речь вводится в авторский контекст без каких-либо специальных средств. При этом чужое слово, как правило, включает либо вопросительное предложение, либо побудительное предложение со значением просьбы, либо представляет собой безличное предложение со значением пожелания, например: 
(9) «О чем вы собираетесь говорить с Юлией Кантор?» Действительно, у нас 25 июня, в воскресенье, в “Прямой речи” на Ермолаевском, 25 Юлия Кантор будет читать лекцию по Тухачевскому (Д. Быков, эфир 03.06.2017);

(10) «Расскажите об отношениях Блока и Маяковского». Ну, видите, отношений-то не было, собственно. Были разовые встречи (Д. Быков, эфир 03.06.2017);

(11) «Хочется передачу о науке». Вы знаете, Евгений, мне тоже хочется передачу о науке. Из Ярославля. Но понимаете, в чем дело, это же такого, как Капица, найти невозможно (А. Венедиктов, эфир 25.08.2017).

Приведенные и подобные примеры показывают, что с помощью нулевого ввода в медиатексты обычно включается прямая речь, представленная законченным высказыванием.

По нашим наблюдениям, воспроизводимое в медиаречи чужое слово может принадлежать различным субъектам. Прежде всего, это радиослушатели, которые присылают свои вопросы либо заранее, либо во время передачи, например:

(12) Михаил Калашников пишет: «Алексей Алексеевич, в последнее время “Эхо Москвы” активно транслирует на видеохостинге Ютуб, скажите, пожалуйста, это временное явление или радиостанция собирается отказаться от Сетевизора. Спасибо, что открыли свой канал в Telegram». Нет, радиостанция не собирается отказываться от Сетевизора, если только Сетевизор не собирается отказываться от радиостанции... (А. Венедиктов, эфир 25.08.2017);

(13) «И сегодня, - пишет мне Анатолий Федоров, - можно учиться в Праге, Барселоне, если есть нормальные мозги и знание языка». Ну да, знание языка - главное... (С. Пархоменко, эфир 25.08.2018).

Смена речевой позиции в медиаречи происходит и в том случае, когда ведущие цитируют писателей, журналистов, экономистов, общественных и государственных деятелей, отдельные средства массовой информации:

(14) В этом рассказе, о котором сам Андреев говорил: «Будьте любезны, не читайте “Бездны”...». Ну, помните, там гимназист Немовецкий гуляет с Зиночкой (Д. Быков, эфир 03.06.2017);

(15) И новость из женского фронта. Максим Шевченко побывал на Курбан-байраме во Владимирской мечети мусульманской общины Владимира и был потрясен презрением властей, которое было предъявлено к людям. Цитирую: «Оно выразилось в том, что для съемок репортажа и поздравления мусульман прислали женщин-журналистов и женщину-чиновника. Большего непонимания и неуважения к людям продемонстрировать было невозможно. Власть, - пишет Шевченко, - не понимает, не чувствует людей, ей плевать на нормы и обычаи, принятые в нормальном человеческом обществе» (Ю. Латынина, эфир 25.08.2018);

(16) Вот, есть знаменитый отчет аналитика Сбербанк СІВ Александра Фэка, который стоил ему работы, который написал, что ни один трубопроводный проект Газпрома не окупается, что они строятся не в интересах акционеров, а в интересах подрядчиков (Ю. Латынина, эфир 25.08.2018);

(17) Прав совершенно Луначарский, что название поэмы «150000 000» имеет прямое отношение к поэме «Двенадцать» (Д. Быков, эфир 03.06.2017);

(18) А тут вот бедная газета «The Guardian» все время, значит, старается затеять целую кампанию, в которой рассказывается, как на самом деле мусульмане хорошо относятся к женщинам и какие, значит, исламофобы утверждают, что мусульмане не очень хорошо относятся к женщинам (Ю. Латынина, эфир 25.08.2018).

Источником цитирования в медиаречи может выступать гипотетическая речь участников описываемых событий, например:

(19) Есть полулегендарная (возможно, имевшая место) встреча с Блоком - таким, как он запечатлен на единственном кадре кинохроники, когда он стоял в солдатской шинели у Зимнего дворца на Дворцовой площади. Маяковский шел мимо, увидел высокого солдата, узнал в нем Блока. Подошел, поздоровался, спросил: «Как дела?» И тот ответил: «Хорошо. Все хорошо». - «А у меня библиотеку сожгли» (Д. Быков, эфир 03.06.2017);

(20) И с Павлом Дуровым, Виктор, очень смешная история была. Я тут недавно написал Павлу: «Павел, можно я вам позвоню?» Он говорит: «Последний раз я говорил по телефону года 4 назад». Он все переписывается... (А. Венедиктов, эфир 25.08.2017);

(21) И пока он сидел, он вдруг сказал, что он платил... Он вдруг заявил прямо на следствии (потом коммунисты по этому поводу писали запрос), что он платил откаты Володину, который тогда как раз еще был в Саратовской области... (Ю. Латынина, эфир 25.08.2018).

Кроме того, журналисты могут воспроизводить речь героев современных книг и популярных кинофильмов, например: 
(22) Помните, патер Браун говорил: «Я понимаю всех этих людей, потому что я мысленно совершил вместе с ними все эти преступления» (Д. Быков, эфир 03.06.2017);

(23) Я тут напоминала про историю, рассказанную Джорджем Мартином, о Крастере, который жил за Стеной и своих сыновей приносил в жертву белым ходокам, со своими дочерьми спал, и таким образом они были ему жены и он размножался. И при этом говорил, что «я человек богобоязненный» (Ю. Латынина, эфир 25.08.2018).

Диалогические отношения, возникающие в медиатексте между авторской и чужой речью, могут носить как унисонный, так и конфликтный характер. В первом случае констатируется тождественность точек зрения говорящего и субъекта цитируемой речи, во втором - несовпадение их взглядов. В нашем материале представлены и унисонные, и конфликтные диалогические взаимоотношения высказываний в пределах монологического контекста, например:

(24) Тут мне сразу пишут, Григорий из СанктПетербурга: «Доренко с Ликсутовым вас обогнал». Вы знаете, Григорий, неважно кто и с какой скоростью, важны вопросы и ответы. Поэтому обогнать нас не-воз-мож-но. Обогнать «Эхо Москвы» не-возмож-но. Потому что мы лучшие и потому что наши слушатели задают лучшие вопросы... (А. Венедиктов, эфир 25.08.2017).

Согласие или несогласие с адресантом чужого высказывания обычно выражается в следующих за прямой речью авторских комментариях.

Характер диалогических отношений, возникающих между авторским и цитируемым высказыванием в монологической речи, соотносится с той или иной функцией, которую выполняет чужая речь. Современные функционально-стилистические исследования обнаруживают полифункциональность чужой речи, выступающей средством диалогичности в текстах разной стилистической принадлежности. Мы выделяем четыре функции чужого слова, актуальные для современного медиатекста: композиционную, авторитарную, интерпретирующую и конструктивную.

Композиционная функция актуализируется обычно при вводе в монологический контекст вопросов и суждений радиослушателей, что позволяет ведущему перейти к новой теме, например:

(25) «Что хотел сказать Кундера, назвав роман “Невыносимая легкость бытия”?» Неукорененность. Невыносимая легкость вот этого постбытия, постисторического бытия, когда человек в Европе чувствует постепенный отказ от данности, опятьтаки врожденности. Ну, это моя любимая тема, поэтому я понимаю этот роман так: невыносимая легкость неукорененного свободного бытия, невыносимая легкость свободы (Д. Быков, эфир 03.06.2017);

(26) «Уделите минуту роману Горенштейна "Место"? Все же колоссальный (хотя бы по объему) роман». Алекс, роман гениальный. И вот мы как раз сегодня на Круглом столе в «Искусстве кино» с Еленой Михайловной Стишовой - любимым моим критиком и, рискну сказать, социологом от культуры, - мы разбирали «Место»... (Д. Быков, эфир 03.06.2017).

В авторитарной функции чужие высказывания выступают в том случае, когда журналист приводит их или в подтверждение, или для усиления собственных суждений, например:

(27) Так вот. Я повторяю еще раз, что Виктор Суворов, которого я очень люблю, как-то написал замечательную статеечку, в которой как раз говорилось, что, вот, внутренние войска - это нелепость. Войска бывают только внешние. Потому что внутренние войска - это значит, что ты воюешь против собственного народа. И Росгвардия - это преемник и, собственно, продолжение внутренних войск. Поэтому, конечно, соответственно, внутренних войск в США нет. Национальная гвардия там выполняет совсем другие задачи: можно сравнивать только с армией... (Ю. Латынина, эфир 25.08.2018).

Интерпретирующая функция свойственна чужой речи, когда она используется для более убедительного и наглядного толкования приводимого суждения, например:

(28) Единственное, для чего это может делаться, это, конечно, только ради коррупции. И это та ситуация, когда коррупция возводится в политику. Потому что это вообще хрестоматийная вещь. Вот у Адама Смита булочник делает булочки. Что он делает, когда он делает на рынке? Он старается делать как можно лучшие булочки по как можно меньшей цене. А что будет с булочником, если он, допустим, станет зятем короля и получит монополию, и вся страна будет вынуждена только у него покупать булочки? Правильно: он будет произво- 


\section{МАТЕРИАЛЫ И СООБЩЕНИЯ}

дить как можно больше худшие булочки по как можно более высокой цене. Именно это и происходит (Ю. Латынина, эфир 25.08.2018).

Конструктивная функция реализуется в тех случаях, когда журналист вводит чужое высказывание с целью экономии собственных речевых усилий, формулирования мыслей об объекте за счет «чужого слова», например:

(29) Я сначала объявлю тему, потому что старшие товарищи сказали мне, что полезно объявлять какую-нибудь тему, чтобы именно об этом разговаривать с городом (С. Пархоменко, эфир 25.08.2018).

Отметим, что в случаях конфликтности речевого взаимодействия авторского и чужого слова последнее может выступать в композиционной и интерпретирующей функции; при наличии унисонных диалогических отношений в рамках диалога репродуцируемая речь может использоваться в авторитарной, конструктивной, композиционной и интерпретационной функциях.

\section{Заключение}

Проведенный анализ современных медиатекстов позволил установить ряд особенностей их внутренней диалогичности.

Внутренняя диалогичность медиатекста сопровождается модификациями «я»-сферы высказывания, то есть введением в монолог журналиста чужой речи. Специфика форм передачи чужого слова в медиатексте состоит в приоритете прямой речи над косвенной, что в условиях устного общения позволяет максимально четко обозначить границы цитирования.

Включение чужого слова в авторский контекст происходит с помощью глаголов письма и речи, вводных конструкций с указанием на источник цитирования, а также имен и ников приславших свои вопросы радиослушателей. Кроме того, чужая речь может включаться в медиатекст без каких-либо специальных средств. В этом случае она обычно представляет собой или вопросительное предложение, или побудительное предложение со значением просьбы, или безличное предложение со значением пожелания.

В качестве источников цитирования в медиатекстах наиболее актуальны высказы- вания радиослушателей, журналистов, писателей, экономистов, общественных и политических деятелей, героев современных книг и популярных кинофильмов, тексты СМИ.

Для современного медиатекста релевантны четыре функции чужого слова: композиционная, авторитарная, интерпретирующая и конструктивная.

При цитировании между словом автора и чужой речью в медиатекстах могут возникать различные типы диалогических отношений - унисонные и конфликтные.

\section{СПИСОК ЛИТЕРАТУРЫ}

Бахтин М. М., 1993. Марксизм и философия языка : Основные проблемы социологического метода в науке о языке. М. : Лабиринт. 189 с.

Болотнова Н. С., 2009. Коммуникативная стилистика текста : слов.-тезаурус. М. : Флинта : Наука. $384 \mathrm{c}$.

Винокур Т. Г., 1990. Монологическая речь // Лингвистический энциклопедический словарь. М. : Сов. энцикл. С. 310.

Вотрина Е. Н., 2011. Закономерности использования средств внешней диалогичности в научных текстах XX века // Гуманитарные исследования. № 4 (40). С. 90-96.

Дускаева Л. Р., 2012. Диалогическая природа газетных речевых жанров. СПб. : СПбГУ, Филол. фак. 274 c.

Китайгородская М. В., 1993. Чужая речь в коммуникативном аспекте // Русский язык в его функционировании : Коммуникативно-прагматический аспект. М. : Наука. С. 65-89.

Кожина М. Н., 1986. О диалогичности письменной научной речи. Пермь : Изд-во Перм. ун-та. $137 \mathrm{c}$.

Коньков В. И., 2016. Медиаречь: содержание понятия и принципы анализа // Мир русского слова. № 3. С. 58-63.

Котюрова М. П., 2010. Индивидуальный стиль изложения: совокупность логичности, диалогичности и тональности речи ученого // Stil. Beograd. № 9. С. 13-26.

Прохватилова О. А., 1999. Православная проповедь и молитва как феномен современной звучащей речи. Волгоград : Изд-во ВолГУ. 364 с.

Прохватилова О. А., Фотина Н. Э., 2016. Специфика средств внутренней диалогичности в прозе А.П. Чехова 1888-1894 гг. // Вестник Волгоградского государственного университета. Серия 2, Языкознание. Т. 15, № 2. С. 120-128. DOI: https://doi.org/10.15688/jvolsu2.2016.2.14. 
Славгородская Л. В., 1978. О диалогизации научной прозы // Стиль научной речи / отв. ред. Е. С. Троянская. М. : Наука. С. 106-117.

Фотина Н. Э., 2016. Особенности функционирования категории внешней диалогичности в прозе А.П. Чехова // Научный диалог. № 4 (52). C. 84-95.

Чубай С. А., 2005. Внешняя диалогичность современной политической рекламы // Записки Горного института. Риторика в системе коммуникативных дисциплин. Т. 160, ч. 1. С. 97-99.

\section{REFERENCES}

Bakhtin M.M., 1993. Marksizm i filosofiya yazyka: Osnovnye problem sotsiologicheskogo metoda $v$ nauke o yazyke [Marxism and Philosophy of Language: Main Problems of the Sociological Method in the Science of Language]. Moscow, Labirint Publ. 189 p.

Bolotnova N.S., 2009. Kommunikativnaya stilistika teksta: slov.-tezaurus [Communicative Stylistics of the Text. Thesaurus Dictionary]. Moscow, Flinta Publ., Nauka Publ. 384 p.

Vinokur T.G., 1990. Monologicheskaya rech [Monologue Speech]. Lingvisticheskiy entsiklopedicheskiy slovar [Linguistic Encyclopedic Dictionary]. Moscow, Sovetskaya entsiklopediya Publ. 310 p.

Votrina, E.N., 2011. Zakonomernosti ispolzovaniya sredstv vneshney dialogichnosti $v$ nauchnykh tekstakh XX veka [Regularities of Using External Dialogic Means in Scientific Texts of the $20^{\text {th }}$ Century]. Gumanitarnye issledovaniya [Humanitarian Researches], no. 4 (40), pp. 90-96.

Duskaeva L.R., 2012. Dialogicheskaya priroda gazetnykh rechevykh zhanrov [Dialogical Nature of Newspaper Speech Genres]. Saint Petersburg, SPbGU, Filologicheskiy fakultet. 274 p.

Kitaygorodskaya M.V., 1993. Chuzhaya rech v kommunikativnom aspekte [Someone Else's Speech in the Communicative Aspect]. Russkiy yazyk $v$ ego funktsionirovanii: Kommunikativno-pragmaticheskiy aspect [Russian Language in Its Functioning:
Communicative and Pragmatic Aspect]. Moscow, Nauka Publ., pp. 65-89.

Kozhina M.N., 1986. O dialogichnosti pismennoy nauchnoy rechi [On the Dialogic Nature of Written Scientific Speech]. Perm, Izd-vo Permskogo universiteta. $137 \mathrm{p}$.

Konkov V.I., 2016. Mediarech: soderzhanie ponyatiya i printsipy analiza [Mediaspeech: Principles of Analysis]. Mir russkogo slova [The World of Russian Word], no. 3, pp. 58-63.

Kotyurova M.P., 2010. Individualnyy stil izlozheniya: sovokupnost logichnosti, dialogichnosti i tonalnosti rechi uchenogo [Individual Style of Presentation: A Set of Logic, Dialogue and Tone of Speech of the Scientist]. Stil. Beograd, no. 9, pp. 13-26.

Prokhvatilova O. A., 1999. Pravoslavnaya propoved $i$ molitva kak fenomen sovremennoy zvuchashchey rechi [Orthodox Preaching and Prayer as a Phenomenon of Modern Sounding Speech]. Volgograd, Izd-vo VolGU. 364 p.

Prokhvatilova O.A., Fotina N.E., 2016. Spetsifika sredstv vnutrenney dialogichnosti $\mathrm{v}$ proze A.P. Chekhova 1888-1894 gg. [Specificity of Internal Dialogue Means in A.P. Chekhov's Prose of 1888-1894]. Vestnik Volgogradskogo gosudarstvennogo universiteta. Seriya 2. Yazykoznanie [Science Journal of Volgograd State University. Linguistics], vol. 15, no. 2, pp. 120-128. DOI: 10.15688/jvolsu2. 2016.2.14.

Slavgorodskaya L.V., 1978. O dialogizatsii nauchnoy prozy [On the Dialogization of Scientific Prose]. Troyanskaya E.S., ed. Stil nauchnoy rechi [Style of Scientific Speech]. Moscow, Nauka Publ., pp. 106-117.

Fotina N.E., 2016. Osobennosti funktsionirovaniya kategorii vneshney dialogichnosti v proze A.P. Chekhova [Features of External Dialogism Category Functioning in A.P. Chekhov's Prose]. Nauchnyy dialog [Scientific Dialogue], no. 4(52), pp. 84-95.

Chubay S.A., 2005. Vneshnyaya dialogichnost sovremennoy politicheskoy reklamy [External Dialogicality of Modern Political Advertising]. Zapiski Gornogo instituta. Ritorika v sisteme kommunikativnykh distsiplin [Journal of Mining Institute], vol. 160, part 1, pp.97-99. 


\section{МАТЕРИАЛЫ И СООБЩЕНИЯ}

\section{Information About the Author}

Olga A. Prokhvatilova, Doctor of Sciences (Philology), Professor, Department of Natural Sciences and Humanities, Lomonosov Moscow State University, Leninskie Gory, 1, 119991 Moscow, Russia, 12_09@mail.ru, https://orcid.org/0000-0003-0990-8229

\section{Информация об авторе}

Ольга Александровна Прохватилова, доктор филологических наук, профессор кафедры естественнонаучных и гуманитарных дисциплин, Московский государственный университет им. М.В. Ломоносова, Ленинские горы, 1, 119991 г. Москва, Россия, 12_09@mail.ru, https://orcid.org/0000-0003-0990-8229 